\title{
Stylistic Features of Scientific English: A Study of Scientific Research Articles
}

\author{
Jameel Ahmad \\ Jeddah Community College, KAU, Saudi Arabia \\ E-mail: drjameelahmad@rediffmail.com
}

Received: October 13, 2011

Accepted: November 7, 2011

Published: March 1, 2012

doi:10.5539/ells.v2n1p47

URL: http://dx.doi.org/10.5539/ells.v2n1p47

\begin{abstract}
This study intends to explore what stylistic features characterize scientific English and make it different from any other language used in any other discipline. What are certain areas of language that are used more frequently in science than in non-science oriented language texts? This paper deals with the linguistic features concerning the application of vocabulary, grammar, discourse and style used in scientific English. A comparative analysis of literary and scientific language has been undertaken to make the nature and discourse of scientific English clearer. It was found that scientific use of English is marked with accuracy, precision and objective interpretation of facts and findings whereas literary language is subjective interpretation of life. Literary language contains literary impulse and represents the artist's inner self and his spontaneous overflow of feeling whereas scientific language represents universal truth and verifiable research findings. Scientific research papers drawn from Medical and Natural sciences were analyzed and it was found that frequent occurrence of Passive Voice in Method Section of scientific research articles makes scientific research findings impersonal and universal. Scientists use Passive Voice most often in order to get rid of personal whims and fancies. Many other features of scientific English such as nominalization and 'interrogative gambit' which occur frequently as unique discourse features in scientific research journals have also been taken into account in this study.
\end{abstract}

Keywords: Scientific English, Literary English, Impersonalization, Nominalization, Extension of meaning

\section{Introduction}

Heterogeneity of subject matter gives rise to the varied textual and discourse patterns in writing system. Hence the scientific language is not a variety in the same way as the language of literature. In its nature and function, scientific language has proven markedly different from literary language. The scientific language is accurate, precise and detached from individual impulse. It aims to inform about an important issue and what particular approach is taken up to investigate that issue. It is an objective interpretation of facts and findings. It contains such components and findings that need external and experimental evidence to consolidate their validity. On the contrary, literary language is subjective interpretation of life. It represents the artist's inner self. It does not, at all, need external components and evidence to put forth artists' spontaneous overflow of powerful feeling. In scientific text subject-matter takes priority over the style of the linguistic medium (Close, R. 1965). Scientists focus more on the accuracy of theme and the findings rather than on the style of presentation. Hence scientific language is devoid of any sensuous pleasure whereas literary use of language is full of human impulse and human pleasure. Scientific words differ from ordinary and literary words since they do not accumulate emotional associations and implications. Scientific language is supposed to be more direct, free from alternative, and much less artistic than literary language. The language of science is characterized by impersonal style (Ding, D.2002). By impersonalizing, the author implies that there could have been anyone, or any research could have been carried out, the research still would have come to the same conclusion. He is of the view that impersonalization is realized by the frequent use of passive voice. Passive Voice is one of the most frequent, well known and well documented strategies in scientific text. (Swales, 1990). The pursuit of universal generalization in scientific texts enables the author to signal credibility, reliability, objectivity and ultimately authority to their readers and the research community. (Marin, Arrese. J. I, 2002).

\subsection{Literature Review}

Generally speaking, the scientific use of language manifests itself in several ways. The most obvious one was pointed by Strevens in a survey article (1977). He says that scientific discourse uses a lot of words, roots and affixes of Greek and Latin origin, and uses, or has access to, symbols, numbers, and names of chemicals etc which are 
largely international in character. Ewer's findings (1971) about scientific use of language are concerned with technical meaning, frequent use of prefixes and suffixes, structural and qualifying words and phrases. Widdowson (1974) says that scientific language avoids the first and second person thus detaching a message from its sender and receiver. Such depersonalized statement of the scientist represents a way of referring to phenomena in a non-ordinary manner which is as much an essential part of science as is the subject matter. "Scientific writing is the transmission of clear signal to a recipient. Scientific writing needs no ornamentation. Flowery literary embellishment -metaphor, similes, and idiomatic expression are very likely to cause confusion and should seldom be used in research paper". (Robert, A, Day and Barbara Gastel, 2011). Precision is very important in communicating scientific findings. "All scientists must learn to use the English language with precision. (Day, R.A. \& Sakaduski, N. D, 2011). With regard to the grammar, Hilary Glasman - Deal (2009) is of the view that Present Simple tense is used in Introduction Section of scientific research articles to state accepted facts and truths and in Method Section, Simple Past Passive is used, but in Result Section, Simple Past is used. Pauline (1994) states that interrogative gambit is a typical device used in scientific research journals. He found a large number of questions in letters, editorials scientific research articles as part of rhetorical device. Francoise Salager-Meyer (2011) illustrates that hedging is central in scientific writing. It expresses tentativeness, possibility, appropriate accuracy, caution and humility in scientific research articles.

\section{Methodology}

This study contains a contrastive study of two corpora: scientific and poetic language to explore how scientific use of English is different from literary use of English. Poetic language has been compared with scientific use of language. In order to carry out this research 10 scientific research articles drawn from scientific journals such as "The Lancet, BMJ and Down to Earth have been analyzed. These journals are based on research findings of medical and natural sciences. On the other hand poems drawn from classical English poets such as Milton, Spenser, John Keats, Hopkins etc. have been taken up for general linguistic survey. The aim of this contrast is to make the linguistic features of scientific texts clearer and understandable. So the critical analysis of linguistic features in scientific texts has been substantiated by contrastive analysis. The scientific research articles have been analyzed in the light of Swale's (1990) model in order to explore how scientific facts and findings are intrinsically formulated and what kinds of linguistic features govern varied segments of scientific research articles. Those scientific research articles were written by native users of English and published in scientific research journals. Examples from scientific research articles have been given in the present study to consolidate established notions about linguistic features used in scientific texts. Frequency of occurrence of Passive voice in Method Section of scientific research articles has been analyzed by tables and figures. Exact data deduced from tables and figures about the frequency of Passive voice determine the reliability of this study. Grammatical components such as structure of sentences, vocabulary and discourse features used in the organization of scientific research articles have been analyzed thoroughly in this study.

\section{Result and Discussion}

\subsection{Internal Organization of Scientific Research Articles}

The present study explores that the internal organization in scientific research articles based on distinct constituents is a recurrent phenomenon. These constituents contain IMRD sections in scientific research articles which stand for Introduction, Method, Result and Discussion. This set format is followed by the entire scientific community. Introduction Section encapsulates background information with special reference to the established knowledge and findings from the previous researches. Method Section is essentially a listing of procedural formulae and step by step description of what was done in the laboratory. It also describes research apparatus, experimental process and criteria for success. Result Section is concerned with research findings and overall observation made in the study. It illustrates research findings through tables, graphs and pictorials. Discussion Section interprets the significance of the research and justifies it by making reference to the procedures adopted in the study. It also states the limitations of the findings.

\subsection{Stylistic Features of Scientific Text}

\subsubsection{Non-figurative Language}

Scientific text underlines the information without bothering about features that are characteristic of poetic texts, such as rhyme, connotative and symbolic meanings. Literary writers, on the other hand, use a lot of ornaments and figurative language such as (1) allegory in Edmund Spenser's The Faerie Queen, for example, Red Cross Knight is a heroic Knight in the literal narrative, but he is also a figure who is representing everyman in the Christian journey. (2) apologue in George Orwell's famous novel 'Animal Farm'. (3) conceit that is an intellectually ingenious poetic comparison or image such as an analogy or metaphor in which a beloved is compared to a ship, planet, etc. John 
Donne's "Valediction" "Forbidding mourning" for example: "Let man's soul be a sphere. (4) blank verse which represents an unrhymed iambic pentameter. This literary device was used by John Milton in his famous poem 'Paradise Lost". These literary devices are not used at all in scientific texts, because scientists have no intention to make their ideas effective through such literary devices but they substantiate their ideas by logic, examples and experiments. In scientific texts, scientists use no impulse to create additional impressionistic or aesthetic effects beyond that of the dissemination of experimental information. The language of science unlike literary language has realistic and logical implication. Whatever findings are explored or tested by valid experiments are put into exact magnitude. In contrast to this, literary language is not assumed to put forth exact information because its prime aim is not to disseminate information as such but to stir readers' aesthetic sense. Thus Milton's Paradise Lost is read generally as literature and not for accurate religious information because Milton has artistically presented the theme of “man's first disobedience' and tactfully formulated 'Satan's rhetorical speeches. Similarly we don't read Keats' famous poem "Ode to a Nightingale" for any information about the particular species of bird but we read it to explore symbolic implication associated with the bird. The bird has not been described in the poem in realistic terms but in imaginative terms. The description of imaginative bird metaphorically draws our attention to trial and tribulation of life that the poet wants to overcome with the help of imagination such as:

Away! Away! For I will fly to thee

Not charioted by Bacchus and his pards,

But on the viewless wings of poesy. (John Keats)

In the above stanza Keats has delineated an imaginative theme which needs no external evidence or experiment for its validity. He longs to withdraw himself from the stern realities of life on the "viewless wings of poesy". To fly on viewless wings of poesy has symbolic significance. The poet's ultimate resort for relief is poetic imagination. Poetry is his companion which will bring him beyond the worldly fever and fret. In addition to this, the viewless wings of poesy are devoid of scientific and logical implication. In science, it will be wrong to say that poetry has invisible wings. The use of such words and interpretation is admissible only in poetic language, because poetic language is imaginative language which may not be essentially supplemented by logic, reason and argument. In science the entire situation is other way round. Here Newton's Laws of Motion, Kepler's Laws of Planetary and Galileo's Discoveries of Hydrostatic Balance' are not, at all the result of poetic imagination but their findings and discoveries are based on experiments, reason, evidence and logic.

\subsubsection{Non- Deviation from Linguistic Norms}

By this we mean the deviation from the linguistic norms flourishing in poetry which scientific texts often lack. The word 'deviation' for instance, expresses one of the frequent concepts in the description of literary texts whereas deviation rarely occurs in scientific texts. The use of linguistic features is well maintained in scientific composition because any deviation from lexis and syntax in scientific text will, really, mar the easy grasp of the text, hence it is inadmissible. On the contrary, radical deviation from conventional norms of grammar tends to be the common core of poetic language. Grammatical and syntactic deviation which may be considered errors in scientific language becomes the expression of extraordinary worth in literature. Leech (1965) has called such deviation 'foregrounding' and claimed it to be the principles of aesthetic communication. Foregrounding is achieved therefore by the purposeful concentration of certain lexical or syntactic feature. In the following lines the foregrounding is achieved through unusual syntactic order:

(1) Slept Rip Winkle twenty years (Longfellow).

(2) The door is strange to be unlocked. (Dylan Thomas)

(3) When will your round me going end? (Hopkins)

In the normal expression these lines would probably read:

(1) Rip Van Winkle slept for twenty years

(2) It is strange that the door is unlocked.

(3) When will you end your going round me?

In the lines above the usual syntactic order is disturbed because the correspondence between subject and predicate is not regular. The literary artists have taken full liberty to violate the accepted rules of language and created their own rules which are not considered non-language within their own contexts. It is also worth mentioning that in scientific language no such liberty is permissible because in scientific composition, findings are more important than artistic and metaphoric presentation. So to communicate well the findings worldwide is the prime objective of the scientists. 
They do not seek to arouse emotion and present beauty in the language. They rather seek to make themselves understood.

Hunting rhymes are unnecessary and the association of ideas

Which contributes so much to the appeal of the language of

Poetry so much is a nuisance to the scientist. (Brook.G.L. 1981)

The language used in poetry is metaphorical and it itself becomes the object of study. Alliteration, rhythm and the cadence are all essential to create poetic effect but they are all irrelevant in scientific language. Scientists believe in logic and reasons in order to make their experiments and findings valid whereas literary artists lack argumentative progression and reasons. The ideas of artists are based on intuitive occurrence which requires no experimental validity at all. The scientists represent the truth which has universal appeal because it is pertinent to experiment and logic. But the literary artists delineate truth which is based only on his inner and personal feeling.

\subsubsection{Use of Passive in Scientific Writing}

Passive Voice is one of the most well-known features of scientific writing. This is frequently used in scientific writing to create an impersonal scientific text. It has become a cliché to say that the passive form is a feature of scientific prose and that is so because of the impersonal nature of scientific writing. The technical writers in order to remain objective and impersonal choose passive form because the important idea is not who did something but what was done. The passive verb will be a better choice to describe experimental procedures in Method Section of scientific research articles. Previous studies have also identified this type of impersonalization by means of passive voice. (Gilbert 1976; Vande Copple 1994; Hyland 1996; Ding 2002; Dorgeloh. H. 2004). Many scientists and engineers believe that everything should be written in passive voice. They avoid using active voice because they feel it would be too strong and doesn't fit in their professional character. All the research methodologies and the research tools used for experiments in scientific research are put forth in Passive Voice. The statistical findings of active and passive use in scientific research articles are as follows:

[Insert Table $1 \&$ Figure 1 Here]

The present statistical finding is a clear pointer to the predominant occurrence of passive verbs in scientific research articles. A corpus of 10 scientific research articles written by native users of English was drawn from medical and natural sciences. These scientific research articles were analyzed statistically in order to determine the frequency of occurrence of Passive voice. Out of 565 running words the frequency of Passive Verbs in scientific research articles has gone up to $70 \%$ whereas the overall ratio of Active Voice has gone up to $30 \%$ only. The aim to use passive form in Method Section of scientific research article is to make the research findings universally acceptable and to get rid of personal whims and fancies.

[Insert Table 2 \& Figure 2 Here]

The second table demonstrates the frequency of occurrence of Active \& and Passive Voice in different sections of 10 scientific research articles. The predominant occurrence of Passive Voice lies in Method Section. It has gone up to $50.63 \%$ whereas the use of active voice has gone up to $11.76 \%$ only. In Result Section also the percentage of passive voice is higher than that of active voice. But the use of passive voice in Result Section has gone up to $20.25 \%$ whereas the use of active voice has gone up to $17.64 \%$. In Abstract, Introduction and Discussion sections the frequency of active voice is more than that of passive voice but only with a little margin. In addition, the preponderance of passive form in Method Section reflects the fact that the researcher explains the procedural formula offering the step-by-step residual description of what was done in laboratory. Hence the passive voice has been found more frequent in scientific research articles notably in the objective, non-personal style of scientific articles and news items. MacDonald (2002) also stated that the Method section in scientific research articles relies heavily on passive voice.

\subsubsection{Rhetorical Meaning in Scientific English}

The quest for intellectual growth leads to new discoveries through which common words are charged either with new meanings or they are employed to represent newly established entities. Trimble (1985) has termed this process "technicalizing processes". This device is evolved to interpret and to reclassify the word in a different way from its normal practice in the natural spoken language. The common words when they are compounded and reformulated in the scientific domain, their meanings undergo complete change. Sometimes scientists take ordinary words and give them special dress on varied occasions. Hence a common word after acquiring pejorative connotation means differently in different disciplines. Close, R. (1965) has reinforced the same point by saying:

When every day expressions are defined as technical terms, they are 
defined precisely and may then become distinct from their general use.

Innumerable examples of this type are given below:

Benign: General Meaning: Amiable, generous, In Medical Discourse: It describes a tumor that does not invade and destroy the tissue in which it originates.

Conceive: Common Meaning: to understand, In Medical Discourse: to become pregnant

Mouse: Common Meaning: A small fury animal with a long tail but used metaphorically in computer.

Presentation: common meaning: display, demonstration. In medical discourse: The part of the infant's body that appears first at the opening from the neck of the womb during child birth as perceived on inserting the finger into vagina.

Riddle: Common Meaning: a puzzle in which you ask question. In Agriculture: Box with cross wires at the bottom used for separating out the larger stones from soil and sands.

These scientific words convey entirely different meanings within the ambit of scientific discourse. The process of building up a technical vocabulary involves the naming of the phenomena and then making the name technicalized. This step aims to find the name for the phenomenon. Such a technical taxonomizing is a process of renaming in order to reclassify the vernacular meanings. Once they are reclassified, the vernacular becomes technical and specific to a field. From the foregoing discussion it has now become evident that the scientist in order to evolve a scientific terminology either coins a new word best suited to his purpose or takes the word from ordinary native speech and gives it a special dress for scientific use.

\subsubsection{Use of Nominalization \& Universality of Scientific Discourse}

Another typical feature of scientific English is its nominalization which plays a key role in constituting technicality in scientific discourse. It frequently occurs in scientific texts thereby representing events and qualities of objects not as verbs, adjectives, and adverbs but as nouns. Nominalization allows the scientists to pack complex information into a compact unit. Halliday (1988) claimed that there has been an evolution towards increasing nominalization in scientific writing. For example:
Noun
Verb
Adverb
increases
sharply

(1) The temperature

In this sentence the subject is a Noun and the verb a material process which may also be expressed as:
Adjective
Noun
NA
A sharp
increase
in temperature

In this sentence the verb 'increase' has been nominalized and the adverb 'sharply' has become an adjective in theme position.

(2) Qualities can also be nominalized. For example:

'An electron moves in an orbit' becomes 'the orbital motion of an electron'

One more prominent feature of scientific English is its universality. That is to say the terminologies used in scientific text are universally acceptable because they are based on experiment, reason and rationale. In fact scientists use English and shun all such perception and interpretation that have no empirical validity. They present only those findings which are proven by experiment. Scientists while communicating their findings are, not at all, governed by impulse and personal temperament. So the language they use gets rid of personal coloring and hence it becomes universal. Scientists use English to realize universal sets of concepts, methods, and procedures which are independent of social and cultural influences. This further leads to the unity of scientific rhetoric which is accepted worldwide. In fact, scientific English is regarded as a powerful means to realize universal notions associated with scientific enquiry. Scientific discourse is a universal mode of communicating or universal rhetoric which is realized by scientific text in different languages by the process of textualization.

\subsubsection{Use of Questions in Scientific Research Articles}

Scientists are likely to face strong opposition while communicating their findings so they use different devices to fight their ideas as well to get their works published. Most prominent and useful among them is "interrogative gambit" which is a typical device used in scientific journals to popularize facts and findings. The use of questions in the organization of discourse is a very strong rhetorical device because it enables the writer to catch the readers' quick response and to make up their minds for the follow up. Questions are used to arouse readers' interest as discourse organizers. It has been found that questions are frequently used in the titles of scientific articles in order to 
draw readers' attention and to pinpoint the main topic of the research .Example of such type are given below:

(1) Farce on wrong flows? (2) For a safer landing? (3) Frayed and facilities? (4)Cooling interference?

Interrogatives are frequently used when the author tends to provide framework for the discourse. The author will pose question or a series of questions in the first paragraph and the rest of the article will consist of the author's own answer to the questions asked at the beginning. This again is to arouse the reader's interest and to create anticipation. A series of questions that are put forth in the beginning introduce the main aspects of the problems to be addressed in the text. The use of question also serves readers to move from old to new information and it calls to the readers' mind the information they already posses and prepare them for what is to follow. Examples of such techniques are given below:

How are the scientists to face the challenge? (Down to Earth)

The rest of the article is basically a series of suggested answers to this question which represents the author's standpoint. This is a good example of this discourse technique. There are also examples where the writer poses a question at the outset which later on is followed by interpretation and details such as:

Why should we bother to draw attention to the manufacturing of sophisticated weapons? (Down to Earth)

Interrogative forms are also used when the writer is addressing a highly complex subject. In this case no explicit answers are given. The issue is considered open to debate. The questions are usually spread throughout the text in this case. The examples are given below:

(1) Who has the right to know of an individual's genetic make up? And what use may be made of this knowledge?

(11) Should we add laws against discrimination on the grounds of genetic make up to these against discrimination on the grounds of race, religion and gender? (The Lancet)

In the above sentences the writer has used a series of questions which stir readers' mind to think on several aspects of the subject which is fraught with ethical and scientific problems. Sometimes the rhetorical question is used to indicate provocative note which signifies the author's attitude. Such as:

If mothers have the right to bear children with aids, why can they not choose to have a genetic defect connected and so to pass it on to their children? (The Lancet)

Sometimes questions are used to point to the future with suggestion for debate or future research or as a kind of punch line to end the article. Such example has been found in an editorial form "The Lancet". Here the question has been used in the last paragraph. After a discussion covering three paragraphs the final paragraph starts.

(1) Is there transcription as yet undetected at an extremely low level from the HSW genome? (The Lancet)

(11) What is the role, if any' of the cell genome in the control of latency? (The Lancet)

(111) Are there cellular sequences analogous to the latency associate transcripts? (Scientific American)

The use of questions in the last paragraph indicates gaps in present knowledge and makes an appeal to continue research in the field. This is the best way to appeal directly to the reader in a genre where direct second person statements are extremely rare. There is no answer provided and thus the whole subject is left open. It leaves the reader with a handful of future issues and unresolved problems to ponder on. Hence it could be deduced that the use of questions in scientific texts creates anticipation, arouses interest, and challenges readers for thinking about the topic of the text. Questions have a direct appeal in bringing the second person into a kind of dialogue with the writer which other rhetorical devices do not have to the same extent.

\subsubsection{Use of Hedges in Scientific Research Articles}

Hedging, the expression of tentativeness and possibility is often held to be an important feature of scientific discourse Hedging can be applied to increase conceptual fuzziness when information such as exact reference or precise numerical is unobtainable or unnecessary in view of the needs of the readers. Therefore, a relatively low degree of exactitude partly accounts for the occurrence of hedging devices, for example, by using the epistemic model auxiliaries, tentative reporting verbs, tentative nouns and the like. In addition, scientist also can signal to the readers that what is said should not be perceived as the only possible interpretation. Thus hedging can be used to adjust scientific activities according to the non-specialist audience. Since scientist must present himself as a sincere student of discipline while asserting his individual contribution, he has to be cautious in how he defines his relationship to a specialist or a layman. So the use of hedges to express ideas is a crucial means of achieving a close fit between the scientist's statement and consensus of readers. Today's scientists are urged to use a style of writing 
which projects both personal modesty and honesty. They are well aware of the fact that arrogance and exuberance are not well regarded by the scientific community. Salager (1994) is also of the same view when he says:

When a scientist goes to the heart of the matter, he is open to attack. As a consequence everything must be toned down; speculation can obviously be made but it must be apologized for.

In order to reach this goal a scientist has a variety of linguistic devices available which generally go under the rubric of hedges. The taxonomy of hedges as identified linguistically is as follows:

(1) Epistemic main verbs such as ("to indicate, to suggest, to propose, to tend, to seem, to appear) etc.

Example: The previous researchers suggest that the worms living in the host body whether alive or dead appear to release certain metabolites. (Metabolic Process of Worms .IMA)

(11) Epistemic modal auxiliaries such as (may, might, can, could etc.)

Example: while particular antibodies may play a crucial role in the pathogenesis of disease. (Remedy in Pathogenesis of disease, Scientific American)

(111) Epistemic Adverbs: such as hypothetically, probably, likely etc.

Example: In the absence of randomized trials these data probably provide reliable estimate of outcome for patients treated with observation and delayed hormone therapy. (The New England Journal of Medicine).

\section{Conclusion and Implication}

The above mentioned features of scientific English tend to cluster together as characteristic of scientific discourse. They are not arbitrary but have evolved to meet the needs of scientific method, argument, experiments and theories. The scientific use of language is devoid of any emotional expression. It is purged from an individual, whims and fancies. On the contrary, literary use of language is embedded in an emotive feeling and human impulse. A literary writer mainly focuses on the style of presentation. 'What oft was thought but never so well expressed' is the essence of literary writing. The internal formatting pattern such as Introduction, Method, Discussion and Result sections (IMRD) in scientific research articles is a recurrent phenomenon. The scientist, through this pattern, designs the conceptual framework of his research and organizes his research findings in coherent manner. In addition, the frequent use of Passive Voice in Method Section of scientific research journals is a distinguished feature. The entire scientific community living in any country frequently uses Passive Voice in Method Section. Scientists are of the view that by using Passive Voice, they can get rid of personal imaginative feeling and can remain objective while verifying their research findings thereby making their findings universally acceptable. The result of the current study about Passive Voice will be immensely useful for the novice researchers of science, because it can help them to write their research papers with grammatical accuracy and organize their findings in a systematic manner. Findings about different functions of interrogative form in scientific research articles are also very significant. They will make the researchers familiar with how to arouse interest and curiosity about scientific issues among readers by putting questions. Discussion about hedging device in this study is equally important for the scientists, because by using this device they can increase the acceptability of their findings and result.

\section{References}

Brook, G. L. (1981). Words in Everyday Life. London, Macmillan. p. 48

Close, R. (1965). English We Use for Science. London, Longman.

Day, R. A., Sakaduski. N. D. (2011). Scientific English: A Guide for Scientists and Other Professionals. (3rd ed) Greenwood. p. 4. [Online] Available: http://www.abc-clio.com/product.aspx?id=2147491826

Ding, D. (2002). The passive voice and the social values in science. Journal of Technical Writing and Communication, 32, 137-154. [Online] Available: http://baywood.metapress.com/app/home/contribution.asp?referrer=parent\&backto=issue,4,6;journal38,162;linkingp ublicationresults, $1: 300326,1$

Dorgeloh. H. (2004). The limits of variation in scientific writing: Syntactic and functional constrains. I T L. Review of Applied Linguistics, 143/144, 199-222. http://dx.doi.org/10.1177/0741088307302946

Ewer J. R. (1971). Further notes on developing an English programme for students of science and technology. English. Language Teaching Journal, 26(1), pp. 65-70. http://dx.doi.org/10.1093/elt/XXVI.3.269

Francoise Salager-Meyer. (2011). Scientific discourse and contrastive linguistics: hedges. European Science Editing, 37(2). p. 36. [Online] Available: http://www.ease.org.uk/pdfesearticlesmay11/salager-meyerArticle35-37.pdf 
Gilbert, G. N. (1976). The transformation of research findings into scientific knowledge. Social Studies of Science, 6, 281-306. http://dx.doi.org/10.1177/030631277600600302

Halliday, M. A. K. (1988). On the language of physical science. In M. Ghadessy (ed.), Registers of Written English: Situational features and linguistic features. London: Pinter. pp. 162-178

Hilary Glasman-Deal. (2009). Science Research Writing for Non-Native Speakers of English (1 ${ }^{\text {st }}$ Edition). Imperial College Press.

Hyland, K. (1994). Hedging in academic writing and EAP textbooks. English for Specific Purposes. http://dx.doi.org/10.1016/0889-4906(94)90004-3

Leech, G. (1965). This Bread I Break ... language and Interpretation(ed). Teaching Literature Overseas.

MacDonald, M. N. (2002). Pedagogy, pathology and ideology: The production transmission and reproduction of medical discourse. Discourse and Society, 13, 447-467. http://dx.doi.org/10.1177/0957926502013004453

Marin Arrese, J. I. (2002). Mystification of agency in passive, impersonal and spontaneous situation types. In Conceptualization of Events in Newspaper Discourse. [Online] Available: http://www.ucm.es/info/fing1/psl/Research/Marin\%20Arrese\%20JI\%20ed.pdf

Pauline Webber. (1994). The function of questions in different medical journal genres. English for Specific Purposes, Vol.13. http://dx.doi.org/10.1016/0889-4906(94)90005-1

Robert A Day, and Barbara Gastel. (2011). How to Write and Publish a Scientific Paper. ( $7^{\text {th }}$ ed.) Santa Barbara, Calif: Greenwood. $\quad$ p. $3 . \quad$ Online] Available: http://www.worldcat.org/title/how-to-write-and-publish-a-scientific-paper/oclc/696099330

Salager, M. (1994). Hedges and Textual Communicative Function in Medical English written Discourse. ESP. http://dx.doi.org/10.1016/0889-4906(94)90013-2

Strevens P. (1977). Special Purpose Language learning: a perspective. Language Teaching \&Linguistic Abstracts, 10(3), 145-163. http://dx.doi.org/10.1017/S0261444800003402

Swales. (1990). Genre analysis: English in academic and research settings. English for Specific Purposes, 20, 439-458

Trimble, L. (1985). English for Science and Technology. A Discourse Approach. London, Cambridge University.

Vande Kopple, W. J. (1994). Some characteristics and functions of grammatical subjects in scientific discourse. Written Communication, 11, 534-564. http://dx.doi.org/10.1177/0741088394011004004

Widdowson H. G. (1974). Literary and scientific uses of English. English Language Teaching Journal, 28(3), 282-292. http://dx.doi.org/10.1016/0889-4906(91)90015-O

Table 1. Use of Active \&Passive Voice in Scientific Research Articles

\begin{tabular}{|l|l|l|}
\hline Total N0 of Active \&Passive used & 565 & Percentage \\
\hline Active Voice & 170 & 30 \\
\hline Passive voice & 395 & 70 \\
\hline
\end{tabular}

Table N0: 1 Statistical Data

Table 2. Use of Active and Passive Voice in different sections of Scientific Research Articles

\begin{tabular}{|l|c|c|}
\hline & Active Voice & Passive Voice \\
\hline Abstract & 11.76 & 7.59 \\
\hline Introduction & 29.41 & 10.12 \\
\hline Method & 11.76 & 50.63 \\
\hline Result & 17.64 & 20.25 \\
\hline Discussion & 29.41 & 11.39 \\
\hline
\end{tabular}




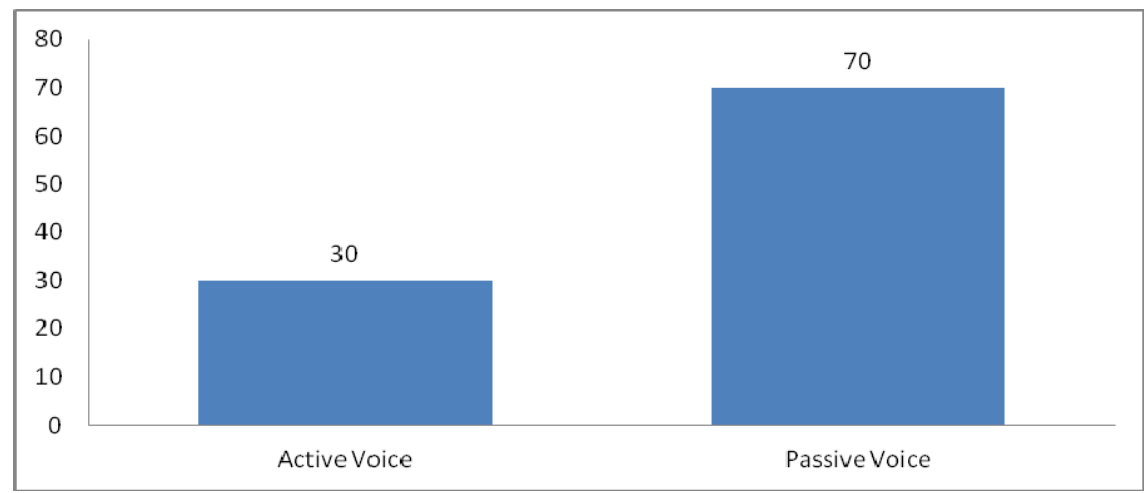

Figure 1

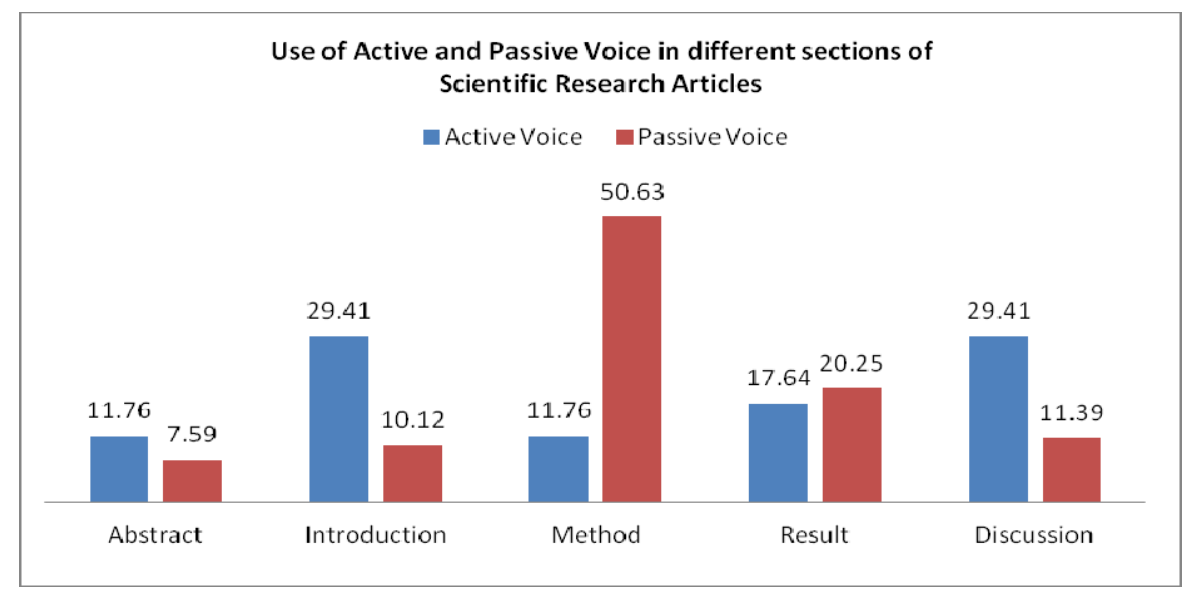

Figure 2 